\title{
The effect of the suggested exercises to Coordination on some of the physical variables, and the level of skill performance of the handball players during matches *Dr/ Khaled Hussein Mohammed Aly
} Introduction and research problem:

Sports training is considered one of the humanities, which aims to solve the problems associated with the development of the level of the players, that requires the use of all available means to achieve this aim, due to the multiplicity of those means, capabilities and different levels of the players, this difference requires a creation of different and versatile ideas, to promote the levels of the players,

Handball one of the sports games, which has got a plentiful share, and a multitude of scientific studies for the purpose of the development of physical levels, skill, tactical, and psychological for the players, because its contain the skills that characterized by the speed, different and variable attitudes during the match.

"Kadry Morsy" (2005) believes that the level of the player with the performance of handball skills, determined in the light of physical and kinetic abilities, which enable him to perform these skills, with the maximum efficiency during the match, that requires the development of elements of physical fitness, consisting of those skills, and the form in which lets the player perform these skills, most effectively in the same situation, and throughout the match. $(25: 10)$.

\section{"Kamal Suleiman" (2007)} believes that the need to distinguish handball player with the Coordination between the legs and arms, which contributes to the success of the player of the duties of kinetic performance, as well as reduce the effort, the result not let all the muscles of the body in performance. $(63: 16)$

Several Arabic references have the agreed that, the Coordination means the ability to Consolidating the disparate movements in kind, and the trend among a group of parties, that working together at one time to move the body and its parts with the required accuracy, the order and regulate the movement of these parties to achieve a specific

"|Lecturer, Department of Team Sports Training, Faculty of Physical Education for men, Helwan University

Assiut Journal For Sport Science Arts 
objective of the movement so that the coordination of good time, and place. (66:17), (66: 8), (205: 1), (44:11).

Also, Many of foreign references agreed that, the Coordination is the ability that determines the player potentials, with regard to the harmony of successive, and concurrent movements for body parts, as evidenced by the coordination and integration between independent kinetic systems, and methods of different sensory in the kinetic of rationed patterns that aimed at organizing the body movements, and affect what is preceded or followed by the kinetic or skill performances, which carried out by the body as a whole, according to the precise, economic, and meaningful criteria. (23:26), (26: 24), (15:25).

The

Coordination represents a great importance in the light of being a composite kinetic abilities, which is related to the speed, strength, flexibility, endurance, and expresses the compatibility levels of handball players, the ability to difficult and rapid performance, with various degrees, and highly effectiveness, as considered that the agility, speed, balance, accuracy and performance are from the excellent Coordination requirements. (456: 9), (205: 1), (157: 14), (62:16), (76:17).

In this regard, "Alsayed Abdel Maksoud," (1995) indicated that should there is a sound build to the ability of private and public Coordination in the juniors stage, then

improving it in next stages with other physical attributes, at the same time, so that it has an appropriate effect on the level, As can be seen the need to develop the Coordination, and physical abilities in a combination form, though not to exaggerate the development of physical abilities, and to reduce the compatibility greatly. (4: 48-50).

\section{" Tamer Ewais" (2009)}

believes that the Coordination is a prime rib in the muscle power triangle in light of being the link that allows the player to produce a certain amount of power in less time possible, and to achieve an excellent level of the Coordination, which must be provided sequencing and sequence clearly, sets of muscle in complicated form, as the 
Coordination between the muscle groups of the various body parts, including the legs and arms it works on saving the required energy and reach to the ideal in performance. (5: 85.84).

On the other hand the weights exercises are one of the most common exercises, commonly used in the training of the handball players, especially in the men's team stage which comes effective and fast results, in the development of muscle strength of all kinds, provided that appropriate with the nature of skill performance, in terms of the form of the movement and its speed, But it cannot rely on weight exercises individually, to develop the types of power especially muscle power where it can pose a significant burden on some muscles of the body, that may result in incomplete aspects of skill performance, the compatibility, and the rhythm of a perfect movement, which need to use other methods beside the weights exercises. (5: 96).

In this regard, "Peter\& Will" (2003) indicated that the sports activities that rely on throwing including handball, the throwing speed of the ball, and its accuracy from the player's hand depends on to a large extent on the speed of contraction muscle fibers, making reliance on traditional weight training only impedes the skill performance, in terms of speed, and the required compatibility between the different body parts, such as legs and arms, so that it forces the player keeping weight, and performance, then stop to return to the start position, so this movement slows the speed of contraction muscle fibers, as required for the performance of handball skills. (119: 24).

Through the work of the researcher as a handball coach in several Egyptian clubs, noted that lacking a lot of handball players in the men's team stage to the compatibility between the legs and arms, whereas the skill performance of the players lacks to the efficiency and accuracy in some situations, which require control of the parties the body, especially during the move at high speeds and in different directions, Such as scrolling, the reception of different levels, or dribble, throwing, and deception, whether at the stage of the Fast break, or rapid 
offensive moves, especially tactically during the stage of centers attack, as well as during the skill performance of defense, where it appears in the imbalance of the players with fast performance, especially during physical friction opponent.

As the researcher has noted that in light of his reading, and attending several training courses in handball, the compatibility between the legs and arms, it has not got enough attention, although it has been referenced in several studies, within the ability to kinetic connectivity, as one of the harmonic capacity components, as well as Its rarity special lectures, also the compatibility between the two men, arms and its training, By analyzing the results of scientific studies (22), (12), (20), (21) prove that it handled the compatibility from only the two aspects ,first, is special for junior teams, and second, is the effect of compatibility in the skill learning process, and has not been studying the compatibility of the development of physical and skill condition, and has not been studying the importance of compatibility in the special stage for teams of men whether in terms of team sports in general, and handball in particular.

From the application side The researcher has noted that, lack of attention of many coaches, especially in the men's team stage with exercises that focus on compatibility between the legs, and arms, with the same interest in Other physical elements, which the compatibility exercises have no dedicated time for training, in addition to the loss of interest of the players with importance of performance of compatibility exercises, in case of training it individually, this prompting the researcher as a coach to pay attention to thinking about increasing the difficulty of the exercises represented in addition resistors by certain proportions , so that challenge the players capabilities form in which it forced them to do more, to face these difficulties, to solve some of the problems related to the development of physical and skill level,, through the compatibility exercises between the legs and arms.

Which prompted the researcher to the need to 
develop a proposed exercises, for compatibility in the directions the muscle work between the legs and arms together using weights with a certain proportions of body weight to suit the speed and nature of performance in handball, Gathered in its nature between the components of muscle strength and speed, through a compatibility between the lower and the upper part, to determine the effect of these exercises on some physical and skill abilities of the handball players to the stage of the first men's team during matches.

\section{The research objectives}

This research aims to identify the effect of the proposed exercises on compatibility in some of the physical variables and the level of skill performance for the handball players during matches and through:

1Design of compatibility exercises between the legs and arms by using weights.

2- Identify the effect of these exercises on some physical and skill variables of handball players during matches.

\section{Research hypotheses}

1- There are statistically significant differences between pre-and post-measurement, the percentage of improvement, and the strong influence of the suggested exercises in the physical variables under discussion in a favor of the post measurement.

2- There are statistically significant differences between pre-and post-measurement, the percentage of improvement in a favor of the post measurement.

\section{Research procedures}

\section{The research method:}

The researcher using the experimental method using experimental design, for one set, and the pre-and postmeasurements, due to its relevance of the nature of research.

\section{The research community:}

The research community was the first team players handball, Helioledo Sports Club, and they were registered in the Egyptian Federation of Handball, and participants within the Premier League competitions for season 2013/2014.

\section{The research sample:}

Basic research sample was selected in a manner of comprehensive inventory of all first team players handball in Helioledo Sports Club, totaling (22) players, (2) goalkeepers were excluded. In addition to 
(20) players, as an exploratory sample consists of (10) players the first team Nasr City Club, (registered in The Egyptian Federation of handball to the same degree in the same season), (10) junior players born in 1996 (under 18 years) Helioledo Sports Club, so as to make scientific coefficient of the tests that used in the research.

- The reasons for selecting the sample:

- The availability of the sample under discussion, whereas the researcher works as a Technical Manager for the Handball in Helioledo Sports Club for the season 2013/2014.
- All members of research sample were registered in the Egyptian Federation of Handball for the season 2013/2014.

- All individuals of the research sample are subjected to a training program.

- The homogeneity of the sample:

The researcher has calculated the torsion coefficient of measurements (age, height, weight, training age) as shown table (1), as well as the physical variables under discussion for the players to make sure that the research sample represents the equinoctial distribution in these variables. As shown in

Table (1)

The arithmetic average, standard deviation, and torsion coefficient of research sample in growth rates, and training age $\mathrm{N}=(\mathbf{2 0})$

\begin{tabular}{l|c|c|c|c|c}
\hline \hline Parameter & $\begin{array}{l}\text { Measuring } \\
\text { Unit }\end{array}$ & Average & $\begin{array}{l}\text { Standard } \\
\text { deviation }\end{array}$ & Mediator & $\begin{array}{l}\text { Torsion } \\
\text { modulus }\end{array}$ \\
\hline \hline Length & $\mathrm{Cm}$ & 179.950 & 180.000 & 4.071 & 0.534 \\
\hline Weight & $\mathrm{Kg}$ & 80.700 & 79.521 & 4.658 & 0.937 \\
\hline Age & Year & 26.459 & 26.157 & 4.067 & 0.545 \\
\hline Training age & Year & 14.650 & 15.021 & 2.907 & 0.130 \\
\hline \hline
\end{tabular}

Table (1) shows that all the torsion coefficient values have confined between $(0.130$, 0.937), that these values limited between $(-3,+3)$ which indicates that the sample represents an equinoctial community in those variables.

Table (2)

The arithmetic average, standard deviation, and coefficient of torsion of the physical variables for research sample

$\mathrm{N}=$ (20)

Assiut Journal For Sport Science Arts 


\begin{tabular}{l|l|l|l|l|l|l}
\hline \hline \multicolumn{1}{l|}{ Parameter } & $\begin{array}{l}\text { Measuring } \\
\text { Unit }\end{array}$ & Average & Mediator & $\begin{array}{l}\text { Standard } \\
\text { deviation }\end{array}$ & $\begin{array}{l}\text { Torsion } \\
\text { modulus }\end{array}$ \\
\hline \hline \multirow{4}{*}{$\begin{array}{l}\text { Muscle ability } \\
\end{array}$} & $\begin{array}{l}\text { Arms } \\
\text { Muscle } \\
\text { ability }\end{array}$ & $\mathrm{M}$ & 38.467 & 1.250 & 38.510 & -0.077 \\
\cline { 2 - 7 } & $\begin{array}{l}\text { Legs } \\
\text { Muscle } \\
\text { ability }\end{array}$ & $\mathrm{Cm}$ & 47.065 & 3.198 & 46.500 & -0.34 \\
\hline Running speed & Sec & 3.198 & 0.086 & 3.210 & -0.471 \\
\hline \multirow{2}{*}{$\begin{array}{l}\text { Endurance the } \\
\text { strength }\end{array}$} & Abdomen & Number & 36.500 & 1.850 & 36.000 & 1.275 \\
\cline { 2 - 7 } & Back & Number & 34.500 & 1.821 & 34.500 & -0.320 \\
\cline { 2 - 7 } Agility & Arms & Number & 32.450 & 2.305 & 32.500 & -0.416 \\
\hline Balance & Sec & 23.150 & 0.865 & 23.365 & -0.416 \\
\hline \hline
\end{tabular}

Table (2) shows that all the torsion coefficient values have confined between (1.275, -0.077), that these values limited between $(-3,+3)$ which indicates that the sample represents an equinoctial community in those variables.

Data collection methods and tools

First: Devices and tools:

While the exercises under discussion carried out the following tools have been used:

- Pulleys weights $10 \mathrm{~kg}$.

- Dumbbells 5kg.

- A drawer height $40 \mathrm{~cm}$

- A stop Watch.

- Weights devices (pushing by the front legs while sit pushing by higher than the legs while lying down - the front thigh - back of the thigh).

- A whistle.

To perform the tests under discussion the following tools have been used:
1- Medical Rasta meter Pe 3000 device to measure the height and weight.

2- Plastic cones.

3- Handballs.

4- $\quad$ A Measure Tape.

5- $\quad$ stand

6- legal playing field for Handball.

Second, The questionnaire:

In order to explore the expert opinions (Attachment 1) About:

- The most important physical capacities for the handball that associated with compatibility between the legs and arms. (Attachment 2).

- The offensive and defensive skills are most closely associated with the compatibility between the legs and arms. (Attachment 2).

- the appropriate physical tests to measure physical abilities under discussion. (Attachment 2).

Third, The tests that used in the research (Attachment 3): 
- Vertical jump test of Sargent. (109: 17).

- $\quad$ Throwing Handball Test from the jump to the maximum distance. (13:129).

- Running test for a distance of 20 meters from the high start (187: 13).

- Trunk flexion test from the lying down. (180: 13). -

- Lifting the chest test from the lie down. (18: 455). -

- Barrow test to measure agility. (194: 13)-

(201: 13).
- Lie down oblique test with bend the arms (453: 18).

Fourth: the exploration of the match form:

To measure the performance of the level of some offensive skills from the centers and the Fast break, as well as the level of some defensive skills, during the defense stage against the Fast break, and attack centers. Using exploration of the match form. (prepared by the researcher) (Attachment 5).

Presentation of the results

Table (3)

Significance of differences between the two measures in the preand post-measurements with the physical abilities under discussion. $(\mathrm{N}=\mathbf{2 0})$

\begin{tabular}{|c|c|c|c|c|c|c|c|}
\hline \multicolumn{2}{|c|}{ Parameter } & \multirow{2}{*}{$\begin{array}{c}\begin{array}{c}\text { Measuring } \\
\text { Unit }\end{array} \\
\mathrm{M} \\
\end{array}$} & \multicolumn{2}{|c|}{$\begin{array}{c}\text { Pre- } \\
\text { measurement }\end{array}$} & \multicolumn{2}{|c|}{$\begin{array}{c}\text { Post- } \\
\text { measurement }\end{array}$} & \multirow{2}{*}{$\begin{array}{c}\begin{array}{c}\text { T } \\
\text { Value }\end{array} \\
5.631^{*}\end{array}$} \\
\hline \multirow{2}{*}{$\begin{array}{l}\text { Muscle } \\
\text { ability }\end{array}$} & $\begin{array}{l}\text { Arms Muscle } \\
\text { ability }\end{array}$ & & 38.467 & 1.250 & 40.185 & 1.450 & \\
\hline & $\begin{array}{l}\text { Legs Muscle } \\
\text { ability }\end{array}$ & $\mathrm{Cm}$ & 47 & 3.198 & 49 & 2.348 & $6.868^{*}$ \\
\hline \multicolumn{2}{|c|}{ Running speed } & $\mathrm{Sec}$ & 3.198 & 0.086 & 3.010 & 0.097 & 7.047* \\
\hline \multirow{3}{*}{$\begin{array}{l}\text { Endurance } \\
\text { the strength }\end{array}$} & Abdomen & Number & 36.500 & 1.850 & 39.450 & 2.212 & $7.366^{*}$ \\
\hline & Back & Number & 34.500 & 1.821 & 38.800 & 2.238 & $7.646^{*}$ \\
\hline & Arms & Number & 32.450 & 2.305 & 34.400 & 2.137 & $4.578^{*}$ \\
\hline \multicolumn{2}{|l|}{ Agility } & Sec & 23.150 & 0.865 & 22.378 & 0.703 & $6.851 *$ \\
\hline \multicolumn{2}{|l|}{ Balance } & Degree & 71.900 & 4.711 & 80.500 & 5.871 & $8.900 *$ \\
\hline
\end{tabular}

The Tabulated $(\mathrm{T})$ value at $0.05=2.093$

Table (4)

the rate of improvement between the two measurements the preand post, and effect of strength exercises that being used in physical variables under discussion. $(\mathbf{N}=\mathbf{2 0})$ 


\begin{tabular}{|c|c|c|c|c|c|c|c|}
\hline \multicolumn{2}{|c|}{ Parameters } & $\begin{array}{c}\text { Measuring } \\
\text { Unit }\end{array}$ & $\begin{array}{c}\text { Pre- } \\
\text { measurement }\end{array}$ & $\begin{array}{l}\text { Post- } \\
\text { measurement }\end{array}$ & $\begin{array}{c}\text { The } \\
\text { difference } \\
\text { between }\end{array}$ & $\begin{array}{l}\text { The } \\
\text { improvement }\end{array}$ & $\begin{array}{l}\text { Eata }^{2} \\
\text { value }\end{array}$ \\
\hline \multirow{2}{*}{$\begin{array}{l}\text { Muscle } \\
\text { ability }\end{array}$} & $\begin{array}{l}\text { Arms } \\
\text { Muscle } \\
\text { ability }\end{array}$ & M & 38.467 & 40.185 & 1.718 & $4.466 \%$ & 0.785 \\
\hline & $\begin{array}{l}\text { Legs } \\
\text { Muscle } \\
\text { ability }\end{array}$ & $\mathrm{Cm}$ & 47.065 & 49.210 & 2.145 & $3.315 \%$ & 0.962 \\
\hline \multicolumn{2}{|c|}{ Running speed } & Sec & 3.198 & 3.010 & -0.188 & $5.879 \%$ & 0.968 \\
\hline \multirow{3}{*}{$\begin{array}{l}\text { Endurance } \\
\text { the } \\
\text { strength }\end{array}$} & Abdomen & Number & 36.500 & 39.450 & 2.950 & $8.082 \%$ & 0.671 \\
\hline & Back & Number & 34.500 & 38.800 & 4.300 & $12.464 \%$ & 0.813 \\
\hline & Arms & Number & 32.450 & 34.400 & 1.950 & $6.009 \%$ & 0.687 \\
\hline \multicolumn{2}{|l|}{ Agility } & Sec & 23.150 & 22.378 & -0.772 & $\mathbf{3 . 3 3 5 \%}$ & 0.669 \\
\hline \multicolumn{2}{|l|}{ Balance } & Degree & 71.900 & 80.500 & 8.600 & $11.961 \%$ & 0.995 \\
\hline
\end{tabular}

Tabulated Eata $^{2}$ value from $(0:<0.3$ weak effect $)$, from $(0.3:<0.5$ average effect), from $(0.5:<1.0$ strong effect).

\section{Table (5)}

\section{Significance of differences between the measurement pre-and post} in the offensive skill variables under discussion. $(\mathbf{N}=6)$

\begin{tabular}{|c|c|c|c|c|c|c|c|c|}
\hline \multirow{2}{*}{\multicolumn{3}{|c|}{ Parameters }} & \multicolumn{2}{|c|}{ Pre-measurement } & \multicolumn{2}{|c|}{ Post-measurement } & \multirow{2}{*}{$\begin{array}{c}\text { The } \\
\text { difference } \\
\text { between } \\
\text { two } \\
\text { averages }\end{array}$} & \multirow{2}{*}{$\begin{array}{c}\text { The } \\
\text { improvement } \\
\text { percentage }\end{array}$} \\
\hline & & & \multirow{2}{*}{ Repeation } & \multirow{2}{*}{$\begin{array}{l}\text { Percentage } \\
69.565 \%\end{array}$} & \multirow{2}{*}{$\begin{array}{l}\text { Repeation } \\
33\end{array}$} & \multirow{2}{*}{$\begin{array}{l}\text { Percentage } \\
82.5 \%\end{array}$} & & \\
\hline & Scrolling & successful & & & & & \multirow{3}{*}{1.390} & \multirow{3}{*}{$13.065 \%$} \\
\hline & \multirow{2}{*}{$\begin{array}{l}\text { of } \\
\text { running }\end{array}$} & Failing & 14 & $30.435 \%$ & 7 & $17.5 \%$ & & \\
\hline & & sum & 46 & $100 \%$ & 40 & $100 \%$ & & \\
\hline & \multirow{3}{*}{$\begin{array}{l}\text { Dribble } \\
\text { with } \\
\text { defender }\end{array}$} & successful & 22 & $\% 70.968$ & 20 & $\% 80$ & \multirow{3}{*}{0.776} & \multirow{3}{*}{$9.032 \%$} \\
\hline & & Failing & 9 & $\% 29.032$ & 5 & $\% 20$ & & \\
\hline & & sum & 31 & $100 \%$ & 25 & $100 \%$ & & \\
\hline & \multirow{3}{*}{$\begin{array}{l}\text { Shooting } \\
\text { after } \\
\text { receiving }\end{array}$} & successful & 22 & $68.750 \%$ & 27 & $81.818 \%$ & \multirow{3}{*}{1.223} & \multirow{3}{*}{$13.068 \%$} \\
\hline & & Failing & 10 & $31.250 \%$ & 6 & $18.182 \%$ & & \\
\hline & & sum & 32 & $100 \%$ & 33 & $100 \%$ & & \\
\hline \multirow{6}{*}{ 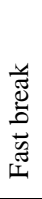 } & \multirow{3}{*}{$\begin{array}{l}\text { Shooting } \\
\text { after } \\
\text { dribble }\end{array}$} & successful & 13 & $56.522 \%$ & 14 & $70 \%$ & \multirow{3}{*}{0.912} & \multirow{3}{*}{$13.478 \%$} \\
\hline & & Failing & 10 & $43.478 \%$ & 6 & $30 \%$ & & \\
\hline & & sum & 23 & $100 \%$ & 20 & $100 \%$ & & \\
\hline & \multirow{3}{*}{$\begin{array}{l}\text { Total } \\
\text { fast } \\
\text { break }\end{array}$} & successful & 89 & $67.424 \%$ & 94 & $797.661 \%$ & \multirow{3}{*}{$2.147 *$} & \multirow{3}{*}{$12.237 \%$} \\
\hline & & Failing & 43 & $32.576 \%$ & 24 & $20.339 \%$ & & \\
\hline & & sum & 132 & $100 \%$ & 118 & $100 \%$ & & \\
\hline
\end{tabular}

\section{Continued Table (6)}

Significance of differences between the measurements pre-and post, in the offensive skill variables under discussion $(N=6)$ 


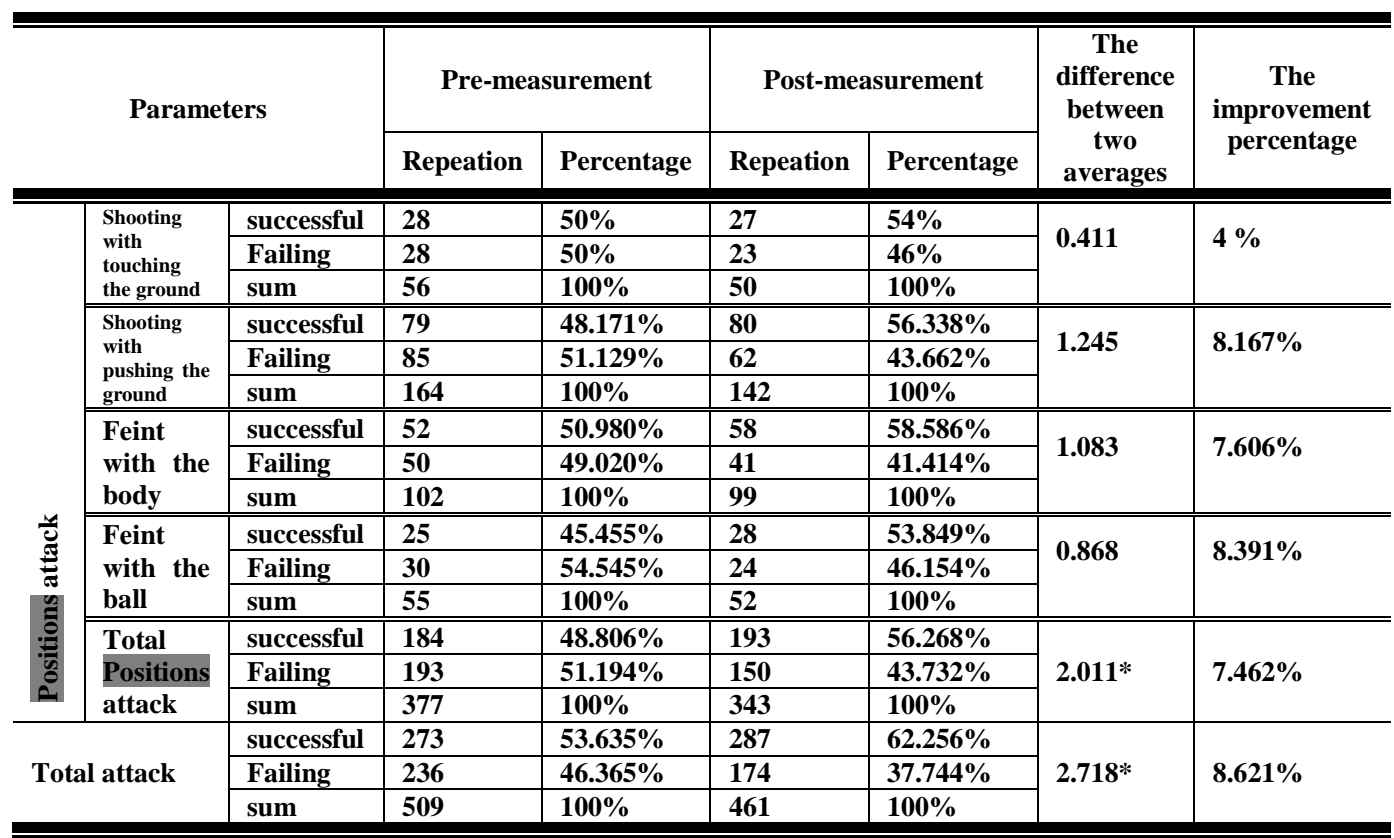

The value of the difference between the two proportions at a certain level $0.05=1.965$.

Table (7)

Significance of differences between the measurements pre-and post, in the defensive skill variables under discussion $(\mathrm{N}=6)$

\begin{tabular}{|c|c|c|c|c|c|c|c|c|}
\hline \multirow{2}{*}{\multicolumn{3}{|c|}{ Parameters }} & \multicolumn{2}{|c|}{ Pre-measurement } & \multicolumn{2}{|c|}{ Post-measurement } & \multirow{2}{*}{$\begin{array}{c}\text { The } \\
\text { difference } \\
\text { between } \\
\text { two } \\
\text { averages }\end{array}$} & \multirow{2}{*}{$\begin{array}{c}\text { The } \\
\text { improvement } \\
\text { percentage }\end{array}$} \\
\hline & & & Repeation & Percentage & Repeation & Percentage & & \\
\hline \multirow{9}{*}{ 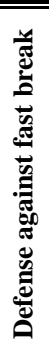 } & \multirow{3}{*}{$\begin{array}{l}\text { Defense } \\
\text { against the } \\
\text { dribble } \\
\text { from } \\
\text { running }\end{array}$} & successful & $\overline{77}$ & $31.818 \%$ & 12 & $48 \%$ & \multirow{3}{*}{1.120} & \multirow{3}{*}{$16.182 \%$} \\
\hline & & Failing & 15 & $68.181 \%$ & 13 & $52 \%$ & & \\
\hline & & sum & 22 & $100 \%$ & 25 & $100 \%$ & & \\
\hline & \multirow{3}{*}{ Steals } & successful & 13 & $35.135 \%$ & 20 & $52.632 \%$ & \multirow{3}{*}{1.526} & \multirow{3}{*}{$17.497 \%$} \\
\hline & & Failing & 24 & $64.865 \%$ & 18 & $47.368 \%$ & & \\
\hline & & sum & 37 & $100 \%$ & 38 & $100 \%$ & & \\
\hline & \multirow{3}{*}{$\begin{array}{l}\text { Blocking } \\
\text { attacker } \\
\text { having } \\
\text { the ball }\end{array}$} & successful & 14 & $51.852 \%$ & 18 & $64.286 \%$ & \multirow{3}{*}{0.935} & \multirow{3}{*}{$12.434 \%$} \\
\hline & & Failing & 13 & $48.148 \%$ & 10 & $35.714 \%$ & & \\
\hline & & sum & 27 & $100 \%$ & 28 & $100 \%$ & & \\
\hline
\end{tabular}

Follow Table (7)

Significance of differences between the measurements pre-and post, in the defensive skill variables under discussion $(N=6)$

Assiut Journal For Sport Science Arts 


\begin{tabular}{|c|c|c|c|c|c|c|c|c|}
\hline \multirow{2}{*}{\multicolumn{3}{|c|}{ Parameters }} & \multicolumn{2}{|c|}{ Pre-measurement } & \multicolumn{2}{|c|}{ Post-measurement } & \multirow{2}{*}{$\begin{array}{c}\text { The } \\
\text { difference } \\
\text { between } \\
\text { two } \\
\text { averages }\end{array}$} & \multirow{2}{*}{$\begin{array}{c}\text { The } \\
\text { improvement } \\
\text { percentage }\end{array}$} \\
\hline & & & \multirow{2}{*}{$\begin{array}{l}\text { Repeation } \\
34\end{array}$} & \multirow{2}{*}{$\begin{array}{l}\text { Percentage } \\
\mathbf{3 9 . 5 3 5 \%}\end{array}$} & \multirow{2}{*}{$\begin{array}{l}\text { Repeation } \\
50\end{array}$} & \multirow{3}{*}{$\begin{array}{l}\text { Percentage } \\
54.945 \% \\
15055 \%\end{array}$} & & \\
\hline & Defense & successful & & & & & \multirow{3}{*}{$2.051 *$} & \multirow{3}{*}{$15.41 \%$} \\
\hline & \multirow{2}{*}{$\begin{array}{l}\text { against } \\
\text { fast } \\
\text { break }\end{array}$} & Failing & 52 & $60.465 \%$ & 41 & & & \\
\hline & & sum & 86 & $100 \%$ & 91 & $100 \%$ & & \\
\hline \multirow{11}{*}{ 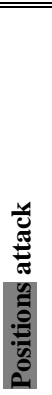 } & \multirow{3}{*}{$\begin{array}{l}\text { Blocking } \\
\text { attacker } \\
\text { having } \\
\text { the ball }\end{array}$} & successful & 150 & $53.191 \%$ & 176 & $61.324 \%$ & \multirow{3}{*}{0.970} & \multirow{3}{*}{$8.133 \%$} \\
\hline & & Failing & 132 & $46.809 \%$ & 111 & $38.676 \%$ & & \\
\hline & & sum & 282 & $100 \%$ & 287 & $100 \%$ & & \\
\hline & \multirow{3}{*}{ Steals } & successful & 17 & $53.125 \%$ & 20 & $64.516 \%$ & \multirow{3}{*}{0.941} & \multirow{3}{*}{$11.391 \%$} \\
\hline & & Failing & 15 & $46.875 \%$ & 11 & $35.484 \%$ & & \\
\hline & & sum & 32 & $100 \%$ & 31 & $100 \%$ & & \\
\hline & \multirow{3}{*}{$\begin{array}{l}\text { Blocked } \\
\text { shots }\end{array}$} & successful & 21 & $50 \%$ & 23 & $\% 57.5$ & \multirow{3}{*}{0.680} & \multirow{3}{*}{$7.5 \%$} \\
\hline & & Failing & 21 & $\mathbf{5 0 \%}$ & 17 & $42.5 \%$ & & \\
\hline & & sum & 42 & $100 \%$ & 40 & $100 \%$ & & \\
\hline & \multirow{3}{*}{$\begin{array}{l}\text { Get rid } \\
\text { of } \\
\text { booking }\end{array}$} & successful & 18 & $47.368 \%$ & 24 & $58.537 \%$ & \multirow{3}{*}{0.994} & \multirow{3}{*}{$11.169 \%$} \\
\hline & & Failing & 20 & $52.632 \%$ & 17 & $41.463 \%$ & & \\
\hline.$\tilde{\Xi}$ & & sum & 38 & $100 \%$ & 41 & $100 \%$ & & \\
\hline 疍 & \multirow{3}{*}{$\begin{array}{l}\text { Total } \\
\text { Defense } \\
\text { against } \\
\text { Positions } \\
\text { attacks }\end{array}$} & successful & 206 & $52.284 \%$ & 243 & $60.902 \%$ & \multirow{3}{*}{$2.456^{*}$} & \multirow[b]{3}{*}{$8.618 \%$} \\
\hline$\underbrace{\pi}_{0}$ & & Failing & 188 & $47.716 \%$ & 156 & $39.098 \%$ & & \\
\hline 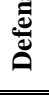 & & sum & 394 & $100 \%$ & 399 & $100 \%$ & & \\
\hline \multirow{3}{*}{\multicolumn{2}{|c|}{ Total defense }} & successful & 240 & $50 \%$ & 293 & $59.796 \%$ & \multirow{3}{*}{ 3.073* } & \multirow{3}{*}{$9.796 \%$} \\
\hline & & Failing & 240 & $50 \%$ & 197 & $40.204 \%$ & & \\
\hline & & sum & 480 & $100 \%$ & 490 & $100 \%$ & & \\
\hline
\end{tabular}

The value of the difference between the two proportions at a certain level $0.05=1.965$.

Interpretation, and discussion the results

\section{Discussion and}

interpretation of results of the first hypothesis:

The results showed in the table of (3) that There are statistically significant differences between, measurement pre and post, and in favor of the post measurement in the variables, muscle power of the arms, legs, and running speed, and endurance the strength of the muscles of the abdomen, back, arms, agility, and balance, The results also showed in the table (8) that the level of these variables improved at rates ranging from $3.315 \%$ to $12.464 \%$, and the results showed in the table (4) the strong influence of exercises that being used in the development of physical variables under discussion ranged between Eata $^{2}$ value of 
0.669 to 0.995 , The researcher attributes this to improvement the level of compatibility between the arms, and legs under the influence of resistors, also the high speed in performing the exercises, These findings are consistent with the study of, "Walid Nashaat" (2009) in that the compatibility exercises have a positive impact in the improvement of level of public and special fitness. (22)

Whereas the proposed exercises contributed to improvement of the level of sequence, and sequencing the work of the muscular group between the upper and lower limbs that led to an improvement in the level of muscular ability of the arms and legs, This is consistent with what referred to it by "Tamer Eweys" (2009) that the Coordination one of a prime rib in the power triangle, also citing "T. Bomba" indicates that the compatibility between the muscular groups working on saving the needed energy for contraction, and to improve communication process between muscular groups of the upper and lower limbs. (85.84: 5).
Also the proposed exercises led to the improvement of the level of running speed, due to the increased step rate, as a result of the performance of the proposed exercises, In addition to improve the level of compatibility between the arms and legs, under the influence of the use of weights, These findings are consistent with the study of "Mamdouh Bayoumi" (2004) that the Coordination exercises have the effect of improvement of variables of step frequency rate average, the times of running, and rates of speed. (21).

Also, exercises have led to the level of improvement in bearing strength of arms, due to the use of weights in suggested exercises in the different muscular directions, In addition to the use of weights for arms in the three axes of proposed exercises, the results also showed that the improvement in the level of agility, so these results are consistent with the study of "Medhat Bahieddin" (2006) in that the compatibility exercises have a positive effect on agility, and it must be combine of the two elements, 
compatibility and agility in the training programs. (20).

Also from the results it is clear that improves balance level, due to the fact that the proposed exercises using the weights of the level of highspeed, in addition to using the arms and legs at the same time in performance, working to improve the balance element so the player can maintain the form of the body during the performance.

In this way, the researcher has check the veracity of the first hypothesis: which states that: "There are statistically significant differences between the pre-and postmeasurements, the proportion of improvement, and the strong influence of the suggested exercises in the physical variables under discussion and in a favor of post measurement."

\section{2- Discussion the results of} the second hypothesis:

Study results in the table (5) showed a statistically significant difference between the measurements pre and post, to the success of the total performance variables in the fast break, the success of the total performance in the Positions attack, and the success of the overall performance in the attack with its two phases (Positions, fast break) in a favor of the post measurement, as The results also showed that improvement in the percentage of the level of skill offensive, both at the stage of the fast break, or the stage of the Positions attack, whereas the rate of improvement in the level of skill performance at some point fast break has ranged from $(9.032 \%$ to $13.478 \%)$, and the proportion of improvement in the level of skill performance at the stage of the Positions attack has ranged from( $4 \%)$ to $(8.621 \%)$.

The

researcher attributes this to the effectiveness of the content of the exercises being used, as it brings these exercises between the two elements-speed performance, and power, as a result of the use of resistors, in addition to compatibility between the arms and the legs, through the rapid performance of these exercises, while maintaining the balance of the body, during the use of resistors and fast performance, Which is makes the these exercises close to a large extent by the nature of the skill 
performance in the stage of the fast break, whether dribble, or scrolling to run fast, or shooting after dribble, or receive the ball from the rapid streaming, which requires the use of different muscular groups, the arms and legs so working on the use of arms in dribble, or scrolling, or shooting of the rapid jump, or run down, with the presence of resistance from the rival either by running or physical friction to disrupt the fast break.

Also in the same table shows that the low repetitions of performance failure for the post measurement less than the pre-measurement, which is consistent with what indicated by "Kareem Murad" (2008) that the Coordination exercises between the arms and legs has a positive effect in reduction of technical errors proportion, as well as reduce errors of throw, during the stage of Fast break in handball. (12).

The results also shown in the table (6) improvement in percentages of the skill level at the stage of the Positions attack, in skill variables under discussion, and through the aggregate level of the shooting with both its types, which refers to the positive effect of training were used, the development level of throw, as contain exercises and suitability with the push the weight by the arm As well as exercises to push the weights by the legs, push the weight by the arms at the same time with a performance as fast as possible, which is similar to a large extent, with the nature of the performance of the skill of the throw in handball, in addition to the improvement of level muscular ability, the arms and legs, according to the shown by the results in the two tables (3), (4), in line with what indicated by the "Kadri Morcy" (2008) pointed out that the development of skill performance, requires significantly raise the elements of physical fitness components of the skill (26:10).

The researcher attributes the disparity in the rate of improvement between the two types of shooting (in touch with the ground, after the pushing the land) to the common use of the skill of shooting while jump, depending on shooting resting on or running or falling, so as it required in the situations of playing during the match. 
The results also showed the improvement in the percentage of the skill of Feint, during the offensive of the Positions, which would indicate the effect of the exercises proposed, which contained some of the partridge forward, and stepping to the side with the move the weight by the arms forward, and beside, so that leads to the improvement in the skill of deception, As required by the skill of a combination of move Besides, then forward with moving the trunk, or move the arm of the ball, taking into account the speed of change of direction, to skip the defender, which led to it exercises, in addition to the improved level of fitness, which indicates an altitude of players to change the direction, The results also showed the in the tables (7), (8) as the researcher believes that the improvement in the performance of the skill of deception is due to the evolution of the players ability on the link between the selected area to perform exercises and maintain speed of performance, while moving the weights by arms, and move the legs with a change of direction, that's what has been taken into account during the design of exercises, This is in line with what referred by "Raczek \& Mynarski" (2002) about the need for spatial perception, the space, time and relationship between the power with movement, through the implementation of the Coordination exercises. (28:25).

The study results showed in the table (7) There are statistically significant differences between the pre and post measurements, to the success variables of the total defensive performance, against the Fast break, the success of the total defensive performance against the Positions attack, the success of the overall defensive performance against the attack with its two phases (Positions, Fast break) in a favor of the post measurement, The results also showed improvement in the percentage of the level of skill of defense, both against the Fast break stage, or stage against the Positions attack, the rate of improvement in the level of defensive skill performance was ranged, At some point Fast break, from (12.434\% to $16.182 \%)$, as the proportion of the improvement in the level of defensive skill 
performance against the Positions attack ranging from $(7.5 \%)$ to $(11.391 \%)$.

According to the researcher this is due to the effectiveness of exercises used in the improvement of defensive performance level for the players of the research sample, where the players performing through different exercises movements in the difficulty, training area, movement trends, in addition to using resistors, which is largely similar to the skill performance such as the disability of acquirer striker of the ball, interrupt and distracting scrolling, in terms of fast moving by the legs, in directions different, with the interruption of the arm of striker, or interrupt the ball, or defense against dribble, as well as skill bulwark, in terms of movement and jump to higher, and moving the arms to repel the ball, And move quickly in a small space, and in different directions to get rid of the detention, whereas the performance of these skills occurs, through the physical friction with opponent, Which is consistent with what indicated by "Ekrami Abdul Hamid" (2012), that the defender must be characterized compatibility between the legs and arms, to be able to anticipate intellectually and physically the striker, so that forces him to perform according his desire, giving him control of the situation, in order to stop the effect of his skill performance, while physical friction with the striker occurs (3).

These results are also consistent with the study of, "Ahmed Mohamed Zaki" (2010) that the Coordination exercises positively contribute to improved defensive performance and the use of tools, devices in compatibility exercises contribute significantly to the defensive performance development as required by the nature of the performance in handball (2).

In this regard, "Kemal Darwish, and others" (1999) state that the nature of the defensive skills performance of the player, and defensive duties, require the need to distinguish the overall compatibility of the body, and the compatibility between the upper and lower limbs (arms legs), where is the compatibility element one of the most important factors that 
help handball player to success in the performance of defensive skills (14: 157).

So, the researcher has check the veracity of the second hypothesis: which states that "there are statistically significant differences between pre and post measurements, and the percentage of improvement in the skill variables under discussion as a result of the use of the proposed exercises, in a favor of the post measurement."

\section{Conclusions}

Within the limits of the research problem, and its aim, hypotheses and the nature of the sample, the researcher finds the following conclusions:

1- Use of the proposed Coordination exercises led to statistically significant differences at the level significantly (0.05) between the two measurements pre-and post in the variables (the muscle power of the legs, arms, starting speed, endurance strength of the arms, abdomen, back, agility, and balance) in a favor of the post measurement. 2- Use of the proposed Coordination exercises has a strong effect led to an improvement in the levels (the ability of the legs muscle, arms, starting speed, the strength of endurance arms, abdomen, back, agility, balance) percentages ranged from $(3.315 \%$ to $12.464 \%)$.

3 - Use of the proposed Coordination exercises, has led to statistically significant differences at the level significantly (0.05) between the two pre-and postmeasurements in the percentages of success and failure the variables offensive skill (Total offensive performance skills in the Fast break, the total performance skills in the Positions attack, the total performance skills in the attack with its two phases, Fast break, and Positions) in a favor of the post measurement. 4- Use of the proposed Coordination exercises, has led to statistically significant differences at the level significantly (0.05) between the two pre-and postmeasurements in the percentages of success and failure the variables defensive skill (Total defensive performance against the Fast break, the total performance against the Positions attack, the total performance skills in the attack with its two phases, Fast 
break, and Positions) in a favor of the post measurement.

5- Use of the proposed Coordination exercises led to an improvement in the variables of level of offensive skill performance under discussion percentages ranged from ( $4 \%$ to $13.48 \%$ ), and defensive skill performance variables (under discussion) percentages ranged from $(7.5 \%$ to $17.50 \%$ ).

\section{Recommendations}

1 -Need to focus on Coordination exercises for the handball players in the men's stage, and not only to pay attention to compatibility exercises in just juniors' stage.

2 -Use proposed exercises in the development of the physical and skill performance of handball players, because of its positive effect on the development of physical and skill condition.

3 -Attention to the design of further training, Coordination between the legs and arms, using other tools, such as medical balls, elastic cords, and comparison between it and use of weights, in this type of training.

4 -Do further studies to get a better rationing for proposed exercises where the used

weights, and the time of the performance to get the best possible effect for this type of training.

5 -Design similar training exercises of the proposed Coordination program between both sides of the body, right and left, and conduct similar studies on it, to see its impact on the physical and skill variables in handball.

\section{References}

1. Abul Ela Ahmed Abdul Fattah (1997): "Sports training physiological bases", Dar Arab Thought, Cairo.

\section{Adel Abdul Basir} (1998): "Biomechanics and integration of theory and practice in the field of sports", 2nd C, book publishing center, Cairo.

\section{Ahmed Mohamed Zaki} (2010): "Contrast as a base for the training of Coordination abilities and influence in the development of some defensive moves for beginners' handball", scientific production, Physical Education for Boys scientific journal, Alexandria University.

4. Alsayed

Maksoud (1995): "Sports training theories (guide and adjust the level of achievement 
path)", Alhasnaa Library, Cairo.

5. Aweys Aljabali (2000): "Sports training between theory and practice", C1, Dar G.M.S, Cairo.

6. Blume D.D. Zimmermann (1987): Zueinigen wesentlichen Grundpositionen Für die undersushung der koordinationtiven fähigkeiten, theorie und Praxis der körperkultur, P, 29-36.

7. Ekrami Mohamed Abdel-Hamid (2012): "Study of the style of defense by attacking of global levels in handball teams", Master Thesis, Faculty of Physical Education for Boys, Alexandria University.

8. Essam El-Din Mustafa Abdul Khaliq (2003): "Sports training (theoriesapplications)", facility knowledge, Alexandria.

9. Kadri Morsi (2005): "The development of performance skills of handball players", published diary, the Egyptian Handball Federation, Cairo.

\section{Kadri Sayed Morsi}

(1998): "physical training science", published diary, A House for printing, Cairo.

11. Talha Hussain, Mustafa

Kamel, Wafaa Salah (1997):
"Scientific Encyclopedia in sports training", Vol. 1, book publishing center, Cairo.

12. Tamer Aweys Aljabali (2009): "The power in sports activities", b c, Cairo.

\section{Karim Murad Ismail} (2008): " The impact of proposed training program to develop the Coordination abilities to stage fast break in handball", the scientific journal Science of Physical Education and Sports, Faculty of Physical Education, University of Menoufiya.

14. Kamal Abdul Hamid Ahmad, Muhammad Subhi Hassanein (2001): Quad Modern handball", part 1, book publishing center, Cairo.

15. Kamal Darwish, Kadri Morsi, Imad Abbas (2002 : "Measurement and evaluation and analysis of the match in handball", the center of the book for publication, Cairo.

16. Kamal Darwish, Imad Abbas, Sami Muhammad Ali (1999): "Defense in handball", book publishing center, Cairo.

17. Kamal Darwish, Imad Abbas, Sami Mohammed Ali (1998): "The physiological bases for the training of Handball (theories applications)", book publishing center, Cairo. 
18. Kamal

Sulaiman

Hassan (2007): "The performance and teaching handball and applications", C 1, Dar Al alm for publication and distribution.

19. Mohammed Mahmoud Marzouk (2001): "The effect of aerobic and anaerobic capacity development at the level of some of the performances defensive and offensive skills to handball juniors", Ph.D., Faculty of Physical Education for Boys, Zagazig University.

\section{Mohamed}

Medhat

Bahy Alddin (2006):

"Effectiveness of the proposed training program for leaner and Coordination at the level of basic skills offensive basketball juniors", Unpublished MA Thesis, Faculty of Physical Education, Minia University.

\section{Mamdouh Mohamed} Bayoumi (2004): "The effect of muscular Coordination nervous exercises superb speed and some speed changes during the performance stages of the 100-meter racers "(a comparative study), $\mathrm{PhD}$ Thesis, Faculty of Physical
Education for Boys in Cairo, Helwan University.

22. Mohamed

Sobhi

Hassanein (1996): "Correction and Measurement in Physical Education", c 1, Dar Arab Thought, Cairo.

23. - Peter, O., \& Will, G., (2003): The Effeect of Attempted Ballisstic taining on the force of strength and corditioning Research, Vol., (17).

24. -Razek J., Mynarski W., Ljach. (2002): Ksztaltowanie i diaghnozwanie

koordynacyjnych zdolnści motorycznych.

AWF

Katowice. Spor Verlag. Volk und Wissen, Berlien training welkampf (red. G. Scnabel, D. Harra, A. Borde) Sportverlag, Berlin.

25. Walid Nasha't Ali (2009): "The proposed training program for compatibility in their physical and motor skill performance among squash players effect level", Master Thesis, Faculty of Physical Education, Assiut University.

26. William, E.Pretice; get fit sty fit, grawhill U.S.A, 2001. P 2 